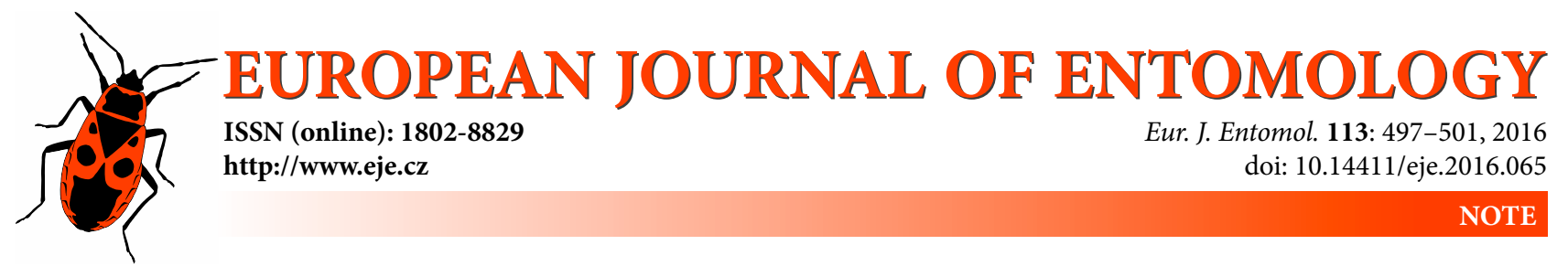

\title{
Settling moths as potential pollinators of Uncaria rhynchophylla (Rubiaceae)
}

\section{DAICHI FUNAMOTO and SHINJI SUGIURA}

Graduate School of Agricultural Science, Kobe University, Rokkodai, Nada, Kobe 657-8501, Japan; e-mails: dai.funamoto@gmail.com, sugiura.shinji@gmail.com

Key words. Lepidoptera, Crambidae, Geometridae, Erebidae, Noctuidae, floral visitors, generalized pollination system, nocturnal moths

\begin{abstract}
Nocturnal pollinators such as moths have received less attention than diurnal insects. To elucidate whether nocturnal moths are important pollinators, we observed both the diurnal and nocturnal visitors to the flowers of Uncaria rhynchophylla (Rubiaceae) in a warm-temperate forest in central Japan. The diurnal visitors included various taxonomic groups (e.g., bees, hoverflies and butterflies). The nocturnal visitors were exclusively moths (Geometridae, Erebidae, Noctuidae and Crambidae). Pollen grains of $U$. rhynchophylla were attached to both diurnal and nocturnal visitors. Although diurnal flower visitors carried pollen grains of other plant species, nocturnal moths did not carry heterospecific pollen grains. These results suggest that nocturnal moths, as well as diurnal insects, are important pollinators of $U$. rhynchophylla.
\end{abstract}

\section{INTRODUCTION}

The vast majority of the studies on plant-pollinator interactions are based on daytime observations (Benning, 2015; Macgregor et al., 2015; Hahn \& Brühl, 2016). However, nocturnal moths are frequently observed visiting various types of flowers (Ikenoue \& Kanai, 2010; Atwater, 2013). Thus, the roles of nocturnal moths as important pollinators are underestimated (Devoto et al., 2011; Atwater, 2013; Macgregor et al., 2015; Hahn \& Brühl, 2016).

Researchers have categorised flower-visiting moths into two functional groups based on their morphology and behaviour (Bawa, 1990; Oliveira et al., 2004; Okamoto et al., 2008; Atwater, 2013). The two groups are small settling moths (e.g., Noctuoidea, Pyraloidea and Geometridae) and long-tongued hovering hawkmoths (Sphingidae). Hawkmoths are frequently investigated in terms of plant-pollinator mutualisms (e.g., Nilsson et al., 1987; Martins \& Johnson 2013; Sazatornil et al., 2016). However, settling moths have received less attention as pollinators than hawkmoths (Okamoto et al., 2008; Atwater, 2013; Wardhaugh, 2015; Hahn \& Brühl, 2016).

Uncaria rhynchophylla (Miq.) Miq. (Rubiaceae) is a vine found in Japan and China (Fig. 1A; Ridsdale, 1978). This vine has spherical inflorescences $(20-25 \mathrm{~mm}$ in diameter; Ridsdale, 1978), each of which is composed of many yellow flowers (Fig. 1B). Previous research reports that $U$. rhynchophylla flowers in a warm-temperate forest on the island of Yakushima in southwestern Japan are visited by diurnal insects such as small bees, vespid wasps and hoverflies (Yumoto, 1987). However, the pollen attached to these flower visitors was not investigated and the observations made only during daytime (Yumoto, 1987).

In Borneo, flowers of another Uncaria species, U. longiflora (Poir.) Merr., are reportedly visited by many kinds of diurnal insects, such as Hymenoptera and Diptera (Momose et al., 1998).
Results from these studies suggest that diurnal short-tongued insects are major pollinators of Uncaria species.

In the genus Uncaria, male reproductive organs are known to mature before female reproductive organs (i.e., protandry; Raju \& Rao, 2016). Uncaria rhynchophylla presents its pollen to vectors on structures other than anthers and in this case the pollen grains are attached to immature stylar heads; a phenomenon referred to as secondary pollen presentation (Fig. 1B; Raju \& Rao, 2016). The styles of $U$. rhynchophylla are exerted from corolla tubes (Fig. 1B-C; Ridsdale, 1978). Therefore, U. rhynchophylla could be pollinated by many different types of insects independent of their morphology. However, U. rhynchophylla has medium-tubed (6-8 mm long) flowers (Ridsdale, 1978), which indicates that $U$. rhynchophylla flowers may attract medium-tongued moths as well as diurnal visitors. To test this prediction, we conducted daytime and night-time observations of $U$. rhynchophylla flowers on the island of Awajishima in central Japan.

\section{MATERIALS AND METHODS}

Field observations were conducted in a warm-temperate forest in Chikusa, Sumoto City, Awajishima, Hyogo Prefecture $\left(34^{\circ} 17^{\prime} \mathrm{N}, 134^{\circ} 52^{\prime} \mathrm{E}, 140 \mathrm{~m}\right.$ a.s.l.). There were many evergreen species of trees, such as Distylium racemosum Sieb. et Zucc., Cinnamomum yabunikkei H. Ohba and Diospyros japonica Sieb. et Zucc. at the study site. The tree canopy along a stream at the study site consisted mainly of Uncaria rhynchophylla. Because individual $U$. rhynchophylla plants could not be distinguished, the survey was carried out along a selected route $(30 \mathrm{~m}$ in length, $3 \mathrm{~m}$ in width). Other plant species, such as Ligustrum japonicum Thunb. and Mallotus japonicus (L.f.) Müll. Arg., were also in bloom along the survey route. One of the two researchers walked 

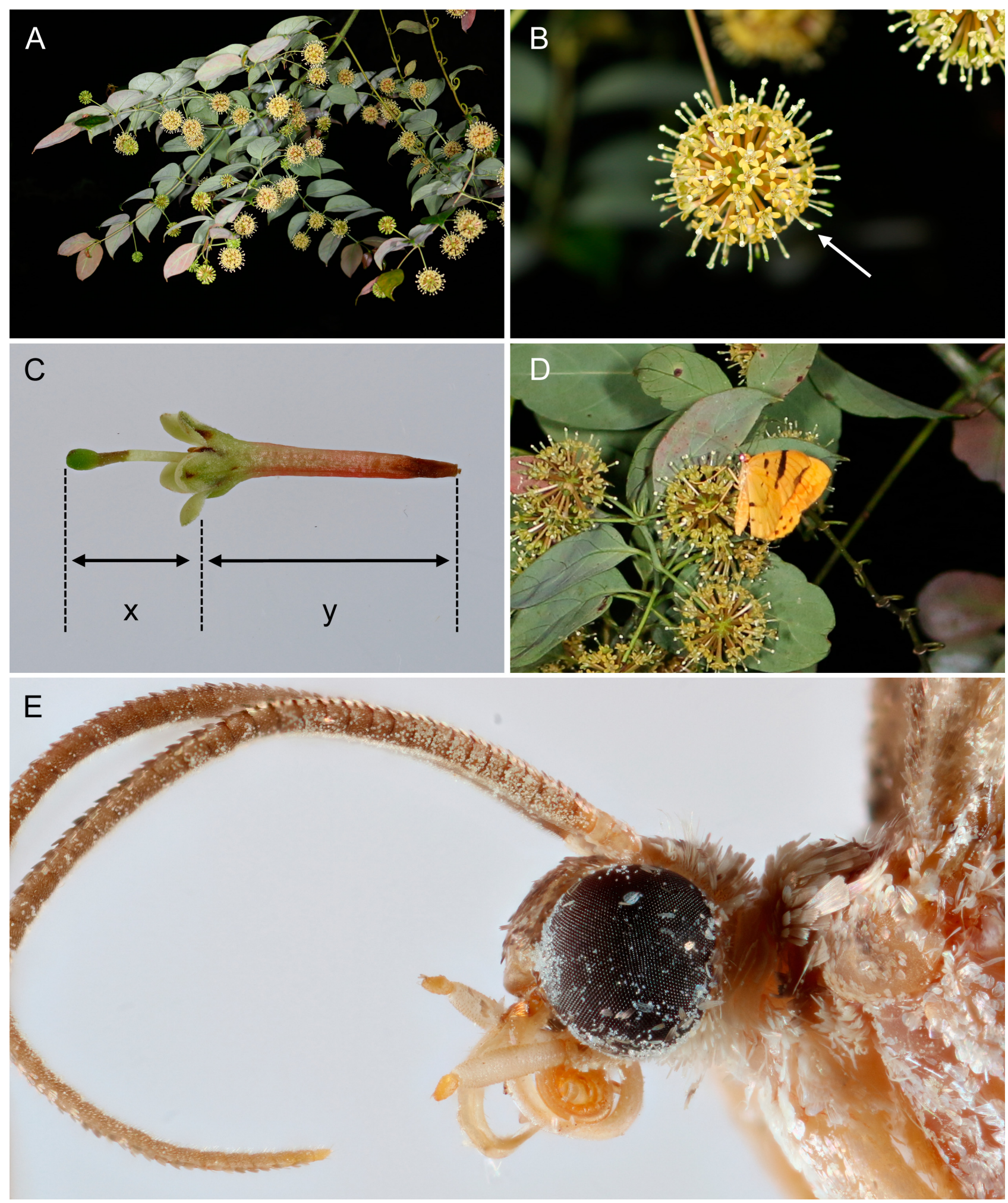

Fig. 1. Flowers of Uncaria rhynchophylla and its insect visitors. (A) Shoots and inflorescences. (B) An inflorescence. The white arrow indicates an immature stylar head with pollen. (C) An individual flower. The distances from the floral entrance to the stylar head (x) and floral base (y) measured (see text for details). (D) A geometrid moth, Gandaritis fixseni, visiting inflorescences. (E) Powder-like pollen grains attached to the antennae, compound eye and proboscis of a geometrid moth, Pseudocollix hyperythra catalalia.

this route at a slow space (ca. 5 min per route) and recorded the insects visiting the inflorescences of $U$. rhynchophylla (height $2.0-5.3 \mathrm{~m})$.

Flower-visitors belonging to seven insect groups (butterflies, bees, hoverflies, flies, wasps, beetles and moths) were recorded. Uncaria rhynchophylla blooming along the survey route were observed for about $17 \mathrm{~h}$ (daytime: $11 \mathrm{~h}$, night-time: $6 \mathrm{~h}$ ) on three days: 19:00-21:00 on 21 June $\left(23.2-23.6^{\circ} \mathrm{C}\right.$, data from the Sumoto Meteorological Station; sunset 19:16), 17:30-21:30 on 23 June $\left(22.3-24.7^{\circ} \mathrm{C}\right.$; sunset $\left.19: 16\right)$, and $09: 50-21: 00$ on 26 June $2016\left(21.5-26.1{ }^{\circ} \mathrm{C}\right.$; sunset $\left.19: 17\right)$. It did not rain during the observation periods. The numbers of inflorescences in bloom along 
Table 1. Frequency of flower visitors.

\begin{tabular}{llcc}
\hline Period & Visitor group & $\begin{array}{c}\text { Total numbers } \\
\text { of visits }\end{array}$ & $\begin{array}{c}\text { Numbers } \\
\text { of visits per hour }\end{array}$ \\
\hline Daytime $^{1}$ & Butterfly & 2 & 0.17 \\
& Bee & 9 & 0.78 \\
& Hoverfly & 5 & 0.44 \\
& Fly & 1 & 0.09 \\
& Wasp & 2 & 0.17 \\
& Beetle & 2 & 0.17 \\
Night-time $^{2}$ & Moth & 21 & 1.83 \\
\hline
\end{tabular}

${ }^{1}$ Daytime: 19:00-19:16 on 21 June, 17:30-19:16 on 23 June, and 09:5019:17 on 26 June 2016. ${ }^{2}$ Night-time: 19:16-21:00 on 21 June, 19:1621:30 on 23 June, and 19:17-21:00 on 26 June 2016.

the survey route were 343 on 21 June, 465 on 23 June, and 286 on 26 June. Because a previous study indicates that very few insects visit the flowers of $U$. rhynchophylla (Yumoto, 1987), it was necessary to observe many inflorescences in order to record most of the potential pollinators of $U$. rhynchophylla.

During the observations, we randomly sampled flower visitors using insect nets (pole length: $1.2-8.0 \mathrm{~m}$ ), to examine the pollen grains attached to them and measure the lengths of their proboscis. In the laboratory, we measured the proboscis length of flower visitors to the nearest $0.1 \mathrm{~mm}$ using slide callipers or with an ocular micrometer under a stereomicroscope. Following the categorisation of Okamoto et al. (2008), we quantified the amount of $U$. rhynchophylla pollen grains on each flower visitor under a stereomicroscope; i.e., the numbers of pollen grains were categorised as $0,1-10,11-100$ and $>100$. We also recorded the presence or absence of heterospecific pollen grains on each visitor. Uncaria rhynchophylla pollen grains could easily be distinguished from those of other species of plants (L. japonicum and M. japonicus) based on their morphological characters (e.g., size) under a stereomicroscope.

To determine the floral morphology of $U$. rhynchophylla we randomly sampled nine flowers collected from nine inflorescenc- es. The lengths of the following two floral parts were measured to the nearest $0.1 \mathrm{~mm}$ using slide callipers: the distances from the floral entrance to the stylar head (x) and floral base (y) (Fig. 1C).

To assess the amount of nectar available during the day and at night, the amount of nectar in corolla tubes was quantified using 1- $\mu 1$ microcapillary tubes (Minicaps; Hirschmann, Heidelberg, Germany). The volume of the nectar sampled was determined by measuring the length of the column of nectar in the capillary tubes and calculating it in terms of the proportion of the entire length of the capillary tube (Morrant et al., 2009). We randomly sampled nine flowers collected from nine inflorescences. Nectar sampling was done during daytime (12:00) and at night (20:30) on 26 June 2016. Because it was difficult to insert microcapillary tubes into the narrow corolla tubes they were cut open to collect the nectar. Nectar concentration was measured using a refractometer (Eclipse 45-81: 0-50\%; Bellingham and Stanley, Kent, UK). As the amount of nectar was too small to directly measure nectar concentration in several nectar samples, one microlitre of water was added to these samples.

Specimen photographs were taken using a Canon EOS 70D camera with a Canon MP-E $65 \mathrm{~mm}$ 1-5× macro lens (Canon Inc, Tokyo, Japan). The software Zerene Stacker v.1.04 was used to stack the images.

\section{RESULTS AND DISCUSSION}

Both diurnal and nocturnal insects visited U. rhynchophylla inflorescences (Table 1). During the daytime, butterflies, bees, hoverflies, flies, wasps and beetles were observed visiting the inflorescences (Table 1). Among the diurnal visitors, bees (mainly male Bombus ardens ardens Smith) were the most abundant visitors (Tables 1, 2). Settling moths of four families (Geometridae, Erebidae, Noctuidae and Crambidae) visited the flowers at night (Fig. 1E; Tables 1, 2). Pseudocollix hyperythra catalalia (Geometridae) was the most abundant species (Table 2). Although a greater diversity of groups were recorded as flower visitors dur-

Table 2. Pollen attached to flower-visiting insects.

\begin{tabular}{|c|c|c|c|c|c|c|c|c|c|c|c|}
\hline \multirow{2}{*}{ Period $^{1}$} & \multirow{2}{*}{$\begin{array}{l}\text { Visitor } \\
\text { group }\end{array}$} & \multirow{2}{*}{ Order } & \multirow{2}{*}{ Family } & \multirow{2}{*}{ Species } & \multirow{2}{*}{$\begin{array}{c}\text { Proboscis } \\
\text { length }(\mathrm{mm})^{2}\end{array}$} & \multicolumn{4}{|c|}{ Uncaria pollen grains $^{3}$} & \multirow{2}{*}{$\begin{array}{c}\text { Heterospecific } \\
\text { pollen }^{4}\end{array}$} & \\
\hline & & & & & & 0 & $1-10$ & $11-100$ & $>100$ & & \\
\hline \multirow{10}{*}{$\begin{array}{l}\text { Day- } \\
\text { time }\end{array}$} & Butterfly & Lepidoptera & Nymphalidae & Argyreus hyperbius (Linnaeus) & 16.3 & 0.0 & 0.0 & 0.0 & 1.0 & 0.00 & $\overline{1}$ \\
\hline & Hoverfly & Diptera & Syrphidae & Eristalis tenax (Linnaeus) & $6.3 \pm 0.2$ & 0.00 & 0.00 & 0.00 & 1.00 & 1.00 & 2 \\
\hline & & & & Syrphinae gen. & 2.2 & 0.00 & 0.00 & 0.00 & 1.00 & 0.00 & 1 \\
\hline & Subtotal & & & & $4.9 \pm 1.4$ & 0.00 & 0.00 & 0.00 & 1.00 & 0.67 & 3 \\
\hline & Bee & Hymenoptera & Apidae & Bombus ardens ardens Smith & $8.7 \pm 0.5$ & 0.00 & 0.00 & 0.00 & 1.00 & 1.00 & 3 \\
\hline & & & Halictidae & Lasioglossum sp. & 4.7 & 0.00 & 0.00 & 0.00 & 1.00 & 1.00 & 1 \\
\hline & Subtotal & & & & $7.6 \pm 0.5$ & 0.00 & 0.00 & 0.00 & 1.00 & 1.00 & 4 \\
\hline & Beetle & Coleoptera & Scarabaeidae & Gametis jucunda (Faldermann) & - & 1.00 & 0.00 & 0.00 & 0.00 & 0.00 & 1 \\
\hline & & & & Cetonia roelofsi roelofsi Harold & - & 1.00 & 0.00 & 0.00 & 0.00 & 0.00 & 1 \\
\hline & Subtotal & & & & - & 1.00 & 0.00 & 0.00 & 0.00 & 0.00 & 2 \\
\hline \multirow{15}{*}{$\begin{array}{l}\text { Night- } \\
\text { time }\end{array}$} & Settling & Lepidoptera & Geometridae & Gandaritis fixseni (Bremer) & $11.1 \pm 0.5$ & 0.00 & 0.00 & 0.50 & 0.50 & 0.00 & 4 \\
\hline & moth & & & Melanthia procellata inquinata (Butler) & 8.3 & 0.00 & 0.00 & 0.00 & 1.00 & 0.00 & 1 \\
\hline & & & & Ourapteryx nivea Butler & 12.3 & 0.00 & 0.00 & 1.00 & 0.00 & 0.00 & 1 \\
\hline & & & & Ozola japonica Prout & 6.9 & 0.00 & 1.00 & 0.00 & 0.00 & 0.00 & 1 \\
\hline & & & & Pseudocollix hyperythra catalalia (Prout) & $5.0 \pm 0.2$ & 0.00 & 0.00 & 0.10 & 0.90 & 0.00 & 10 \\
\hline & & & & Thinopteryx crocoptera (Kollar) & 15.9 & 0.00 & 0.00 & 1.00 & 0.00 & 0.00 & 1 \\
\hline & & & Erebidae & Bastilla maturata (Walker) & 11.1 & 0.00 & 1.00 & 0.00 & 0.00 & 0.00 & 1 \\
\hline & & & & Ericeia pertendens (Walker) & 11.7 & 0.00 & 0.00 & 0.00 & 1.00 & 0.00 & 1 \\
\hline & & & Noctuidae & Peridroma saucia (Hübner) & 10.4 & 0.00 & 0.00 & 0.00 & 1.00 & 0.00 & 1 \\
\hline & & & Crambidae & Botyodes principalis Leech & 14.2 & 0.00 & 1.00 & 0.00 & 0.00 & 0.00 & 1 \\
\hline & & & & Glyphodes onychinalis (Guenée) & 8.9 & 0.00 & 0.00 & 1.00 & 0.00 & 0.00 & 1 \\
\hline & & & & Glyphodes actorionalis Walker & 9.5 & 1.00 & 0.00 & 0.00 & 0.00 & 0.00 & 1 \\
\hline & & & & Bradina geminalis Caradja & 11.4 & 0.00 & 1.00 & 0.00 & 0.00 & 0.00 & 1 \\
\hline & & & & Herpetogramma luctuosale zelleri (Bremer) & 7.3 & 0.00 & 0.00 & 1.00 & 0.00 & 0.00 & 1 \\
\hline & Subtotal & & & & $8.7 \pm 0.7$ & 0.04 & 0.15 & 0.27 & 0.54 & 0.00 & 26 \\
\hline
\end{tabular}

${ }^{1}$ See Table 1 for details. ${ }^{2}$ Mean \pm SE of proboscis length. ${ }^{3}$ Proportion of insects bearing $0,1-10,11-100$ and $>100$ pollen grains of $U$. rhynchophylla. ${ }^{4}$ Proportion of insects with heterospecific pollen. 
ing daytime than at night, nocturnal insects (i.e., moths) more frequently visited $U$. rhynchophylla flowers than diurnal insects (Table 1). Previous studies have shown that the frequency with which the flowers of some species of plants are visited by moths is highest a few hours just after sunset (Sugiura \& Yamazaki, 2005; Okamoto et al., 2008). Because our night-time observations were limited to a 2 -h period just after sunset, the high visitation frequency of moths recorded in this study might be overestimated.

Both diurnal and nocturnal visitors carried pollen grains of $U$. rhynchophylla (Table 2). More than 100 pollen grains were found on each individual of the butterflies, hoverflies and bees sampled (Table 2). Pollen grains were attached to various parts of the bodies (e.g., legs and proboscises) of these diurnal insects. However, no pollen grains were found on the beetles Gametis jucunda (Faldermann) and Cetonia roelofsi roelofsi Harold (Table 2). Pollen grains were also found on $96.2 \%$ of the moths. A total of $54.0 \%$ of the moths carried $>100$ pollen grains (Fig. 1E; Table 2 ). The body parts of the moths to which the pollen was attached were antennae, proboscis, compound eyes and forelegs (Fig. 1E). Thus, all flower visitors (except beetles) are potential pollinators of $U$. rhynchophylla. Although hoverflies and bees carried pollen grains of other plant species (e.g., L. japonicum and M. japonicas), moths and butterflies carried no heterospecific pollen grains (Table 2). Because interspecific pollen transfer has been known to decrease plant fitness by clogging the recipient stigma with heterospecific pollen (Brown \& Mitchell, 2001; Morales \& Traveset, 2008), moths could be more effective pollinators of $U$. rhynchophylla than diurnal visitors that carry heterospecific pollen grains.

The mean $( \pm \mathrm{SE})$ length of corolla tubes was $7.5 \pm 0.1 \mathrm{~mm}$ (y; Fig. 1C) and style exsertion was $4.4 \pm 0.0 \mathrm{~mm}$ (x; Fig. 1C). Nectar was detected in $44.4 \%(\mathrm{n}=9)$ and $22.2 \%(\mathrm{n}=9)$ of the flowers during the day and at night, respectively. Among the flowers containing nectar, the mean $( \pm \mathrm{SE})$ volume of nectar per flower was $0.13 \pm 0.03 \mu 1(n=4)$ during the day and $0.07 \pm 0.01 \mu 1(n=$ $2)$ at night. The mean $( \pm \mathrm{SE})$ sugar concentration of floral nectar was $22.6 \pm 7.2 \%(n=3)$ during the day and $7.7 \pm 0.8 \%(n=2)$ at night. Thus, $U$. rhynchophylla flowers contained more abundant and concentrated nectar during the day than at night. However, we did not experimentally measure nectar production during the day or night. Further experiments are needed to clarify the factors causing such differences in nectar quantity and quality.

Bumblebees, butterflies and some species of moths had proboscises longer $(8.7-16.3 \mathrm{~mm}$ ) than the corolla tubes (Table 2). Because $U$.rhynchophylla flowers contained nectar during the day and at night, these insects might have used their proboscis to feed on nectar. The nectar of $U$. rhynchophylla might be preferred by Lepidoptera because bumblebees and lepidopterans are known to prefer sugar concentrations of $30-55 \%$ and $15-30 \%$, respectively (Willmer, 2011). The proboscises of hoverflies, halictids and a few species of moths were shorter $(2.2-7.3 \mathrm{~mm})$ than the corolla tubes (Table 2), indicating that they could not reach the nectar. In some species of plants, however, accumulations of nectar within floral tubes is known to increase nectar accessibility for shorttongued visitors (Wasserthal, 1997). This situation might occur in the narrow floral tubes of $U$. rhynchophylla and increase the nectar accessibility for short-tongued insects including $P$. hyperythra catalalia, the most abundant species. Pollen grains are important food resources for bees and hoverflies (Proctor et al., 1996). Therefore, short-tongued bees and hoverflies might have visited $U$. rhynchophylla flowers to collect pollen grains.

Nocturnal moths and diurnal insects frequently visited flowers of $U$. rhynchophylla. Pollen grains of $U$. rhynchophylla were found attached to both diurnal insects and nocturnal moths. Although diurnal visitors carried pollen grains of other species of plants, nocturnal moths did not. This is the first study to document the importance of moths as visitors of the flowers of the genus Uncaria. Further experiments are needed to clarify the relative importance of diurnal flower visitors and nocturnal Lepidoptera.

ACKNOWLEDGEMENTS. We thank K. Sakagami (Kobe University) for help with identifying the moths.

\section{REFERENCES}

ATwATER M.M. 2013: Diversity and nectar hosts of flower-settling moths within a Florida sandhill ecosystem. - J. Nat. Hist. 47: 2719-2734.

BAWA K.S. 1990: Plant-pollinator interactions in tropical rain forests. - Annu. Rev. Ecol. Syst. 21: 399-422.

BENNING J.W. 2015: Odd for an ericad: nocturnal pollination of Lyonia lucida (Ericaceae). — Am. Midl. Nat. 174: 204-217.

Brown B.J. \& Mitchell R.J. 2001: Competition for pollination: effects of pollen of an invasive plant on seed set of a native congener. - Oecologia 129: 43-49.

Devoto M., Bailey S. \& Memmott J. 2011: The 'night shift': nocturnal pollen-transport networks in a boreal pine forest. Ecol. Entomol. 36: 25-35.

HAHN M. \& BRÜHL C.A. 2016: The secret pollinators: an overview of moth pollination with a focus on Europe and North America. - Arthropod-Plant Interact. 10: 21-28.

IKenoue T. \& KanaI H. 2010: Nocturnal moth fauna on flowers. - J. Jap. Bot. 85: 246-260.

MacGregor C.J., Pocock M.J.O., Fox R. \& Evans D.M. 2015: Pollination by nocturnal Lepidoptera, and the effects of light pollution: a review. - Ecol. Entomol. 40: 187-198.

Martins D.J. \& Jonson S.D. 2013: Interactions between hawkmoths and flowering plants in East Africa: polyphagy and evolutionary specialization in an ecological context. - Biol. J. Linn. Soc. 110: 199-213.

Momose K., Yumoto T., Nagamitsu T., Kato M., Nagamasu H., Sakai S., Harrison R.D., Itioka T., Hamid A.A. \& Inoue T. 1998: Pollination biology in a lowland dipterocarp forest in Sarawak, Malaysia. I. Characteristics of the plant-pollinator community in a lowland dipterocarp forest. - Am. J. Bot. 85: 1477-1501.

Morales C.L. \& Traveset A. 2008: Interspecific pollen transfer: magnitude, prevalence and consequences for plant fitness. Crit. Rev. Plant Sci. 27: 221-238.

Morrant D.S., Schumann R. \& Petit S. 2009: Field methods for sampling and storing nectar from flowers with low nectar volumes. - Ann. Bot. 103: 533-542.

Nilsson L.A., Johnsson L., Ralison L. \& Randrinjohany E. 1987: Angraecoid orchids and hawkmoths in central Madagascar: specialized pollination systems and generalist foragers. Biotropica 19: 310-318.

Окамото T., Kawakita A. \& Kato M. 2008: Floral adaptations to nocturnal moth pollination in Diplomorpha (Thymelaeaceae). - Plant Spec. Biol. 23: 192-201.

Oliveira P.E., Gibbs P.E. \& Barbosa A.A. 2004: Moth pollination of woody species in the Cerrados of Central Brazil: a case of so much owed to so few? - Plant. Syst. Evol. 245: 41-54.

Proctor M., Yeo P. \& Lack A. 1996: The Natural History of Pollination. Timber Press, Portland, OR, 479 pp.

RAJu A.J.S \& RAO M.M. 2016: Flowering phenology, breeding system, pollinators and fruiting behaviour of Pavetta tomentosa (Rubiaceae) Roxb. Ex Sm., a keystone shrub species in the southern eastern ghats forest, Andhra Pradesh, India. - Ann. Bot. (Rome) 6: 85-96.

RidSDALE C.E. 1978: A revision of Mitragyna and Uncaria (Rubiaceae). - Blumea 24: 43-100. 
Sazatornil F.D., Moré M., Benitez-Vierya S., Cocucci A.A., Kitching I.J., Schlumpberger B.O., Oliveira P.E., Sazima M. \& АмоRIM F.W. 2016: Beyond neutral and forbidden links: morphological matches and the assembly of mutualistic hawkmoth-plant networks. - J. Anim. Ecol. doi: 10.1111/13652656.12509 .

Sugiura S. \& YAMAZAKI K. 2005: Moth pollination of Metaplexis japonica (Apocynaceae): pollinaria transfer on the tip of the proboscis. - J. Plant Res. 118: 257-262.

WARDHAUGH C.W. 2015: How many species of arthropods visit flowers? - Arthr.-Plant Interact. 9: 547-565.
WASSERTHAL L.T. 1997: The pollinators of the Malagasy star orchids Angraecum sesquipedale, A. sororium and A. compactum and the evolution of extremely long spurs by pollinator shift. - Bot. Acta 110: 343-359.

Willmer P. 2011: Pollination and Floral Ecology. Princeton University Press, New Jersey, 778 pp.

Yчмото T. 1987: Pollination systems in a warm temperate evergreen broad-leaved forest on Yaku island. - Ecol. Res. 2: 133-145.

Received July 11, 2016; revised and accepted August 22, 2016 Published online September 27, 2016 